\title{
Overexpression of bovine leukemia virus receptor SLC7A1/CAT1 enhances cellular susceptibility to BLV infection on luminescence syncytium induction assay (LuSIA)
}

Hirotaka Sato ${ }^{1,2}$, Lanlan Bai ${ }^{2,3}$, Liushiqi Borjigin ${ }^{1,2}$ and Yoko Aida ${ }^{1,2^{*}}$

\begin{abstract}
Bovine leukemia virus (BLV) causes enzootic bovine leukosis, the most common neoplastic disease in cattle. We previously reported the development and protocol of the luminescence syncytium induction assay (LuSIA), a method for evaluating BLV infectivity based on CC81-GREMG cells. These cells form syncytia expressing enhanced green fluorescent protein when co-cultured with BLV-infected cells. Recently, we confirmed CAT1/SLC7A1 functions as a receptor of BLV. Here, we focused on CAT1/SLC7A1 to increase the sensitivity of LuSIA. We constructed a bovine CAT1-expressing plasmid and established a new CC81-GREMG-derived reporter cell line highly expressing bovine CAT1 (CC81-GREMG-CAT1). The new LuSIA protocol using CC81-GREMG-CAT1 cells measures cell-to-cell infectivity and cell-free infectivity of BLV faster and with greater sensitivity than the previous protocol using CC81GREMG. The new LuSIA protocol is quantitative and more sensitive than the previous assay based on CC81-GREMG cells and will facilitate the development of several new BLV assays.
\end{abstract}

Keywords: Bovine leukemia virus, Receptor, CAT1/SLC7A1, Luminescence syncytium induction assay, Infection

\section{Main text}

Bovine leukemia virus (BLV), the causative agent of enzootic bovine leukosis, and, a B-cell leukemia/lymphoma, belongs to family Retroviridae. BLV is an oncogenic member of the genus Deltaretrovirus, which also includes human T-lymphotropic virus types 1 and 2 [1]. Currently, BLV is widely distributed in cattle populations [2-7], causing serious problems in the cattle industry without the onset of leukosis. For example, BLV infection

\footnotetext{
* Correspondence: aida@riken.jp

${ }^{1}$ Nakamura Laboratory, Baton Zone Program, RIKEN Cluster for Science,

Technology and Innovation Hub, 2-1 Hirosawa, Wako, Saitama 351-0198, Japan

${ }^{2}$ Virus Infectious Diseases Unit, RIKEN, 2-1 Hirosawa, Wako, Saitama 351-0198, Japan

Full list of author information is available at the end of the article
}

decreases milk production, carcass weight and cow lifespan [8].

BLV is mainly transmitted via cell-containing fluids such as blood and milk by cell-to-cell contact. Although BLV can infect $\mathrm{CD}^{+}{ }^{+} \mathrm{T}$ cells, $\mathrm{CD} 8^{+} \mathrm{T}$ cells, $\gamma / \mathrm{T}$-cells, monocytes, and granulocytes in cattle [9-16], many tumor cells are derived from $\mathrm{CD}^{+} \mathrm{IgM}^{+} \mathrm{B}$-cell subpopulations $[12,17]$. In addition to the many studies showing that the BLV host range is broad, BLV can successfully infect a variety of cells in vitro [18]. We confirmed that cationic amino acid transporter 1 (CAT1/SLC7A1: CAT1), which is ubiquitously expressed on cells in the whole body, functions as a receptor of BLV infection and is responsible for the broad host range of BLV in vitro [19]. CAT1 has 14 potential membrane-spanning domains, is ubiquitously expressed

(c) The Author(s). 2020 Open Access This article is licensed under a Creative Commons Attribution 4.0 International License, which permits use, sharing, adaptation, distribution and reproduction in any medium or format, as long as you give appropriate credit to the original author(s) and the source, provide a link to the Creative Commons licence, and indicate if changes were made. The images or other third party material in this article are included in the article's Creative Commons licence, unless indicated otherwise in a credit line to the material. If material is not included in the article's Creative Commons licence and your intended use is not permitted by statutory regulation or exceeds the permitted use, you will need to obtain permission directly from the copyright holder. To view a copy of this licence, visit http://creativecommons.org/licenses/by/4.0/ The Creative Commons Public Domain Dedication waiver (http://creativecommons.org/publicdomain/zero/1.0/) applies to the data made available in this article, unless otherwise stated in a credit line to the data. 
in a wide variety of cultured cell lines, and plays essential roles in basic cellular function [20].

BLV infectivity is typically measured by the syncytium induction assay (SIA) [21, 22]. We previously developed a method for visualizing BLV infectivity known as the luminescence syncytium induction assay (LuSIA), which uses CC81-BLU3G as a reporter cell line [23]. CC81BLU3G cells are stably transfected with a pBLU3-EGFP reporter plasmid harboring the BLV- long terminal repeat (LTR) U3 region as the promoter and enhanced green fluorescent protein (EGFP) as the reporter gene. When CC81-BLU3G cells are infected with BLV, they form large multinuclear syncytia that express EGFP. To improve sensitivity and reduce background fluorescence, we developed a more sensitive LuSIA using a 2nd generation reporter cell line, CC81-GREMG (GREMG; glucocorticoid response element mutated reporter cording with EGFP), which was stably transfected with a reporter plasmid bearing a mutated glucocorticoid response element on the LTR U3 region promoter [24].

CAT1 protein appears to function as a cell surface receptor for BLV infection [19]. Therefore, CAT1 expression on each cell is correlated with individual cellular susceptibility to BLV infection. In the current study, we predicted that a new LuSIA based on a new reporter cell line overexpressing CAT1 protein would be more susceptible to BLV infectivity compared to the present protocol of LuSIA based on parent CC81-GREMG. We first developed a new reporter cell line, CC81-GREMGCAT1, which showed higher expression compared to the parent CC81-GREMG cells by stable transfection of the bovine CAT1/SLC7A1 expression plasmid and then constructed a 3rd generation LuSIA based on CC81GREMG-CAT1. We then compared the sensitivity of the assay to cell-free infection and cell-to-cell infection evaluated by the 2nd generation LuSIA based on CC81GREMG.

To construct the bovine CAT1-expressing plasmid, RNAs were extracted from the bovine lymphoid cell line KU1 and then reverse-transcribed into cDNA using a high- capacity RNA-to-cDNA kit (Thermo Fisher Scientific, Waltham, MA, USA). CAT1 was amplified by PCR using PrimeSTAR GXL (Takara Bio, Shiga, Japan) and digested by EcoRI and NotI restriction enzymes and ligated into the pME18neo expression vector. The neomycin resistance gene was recombined with the hygromycin

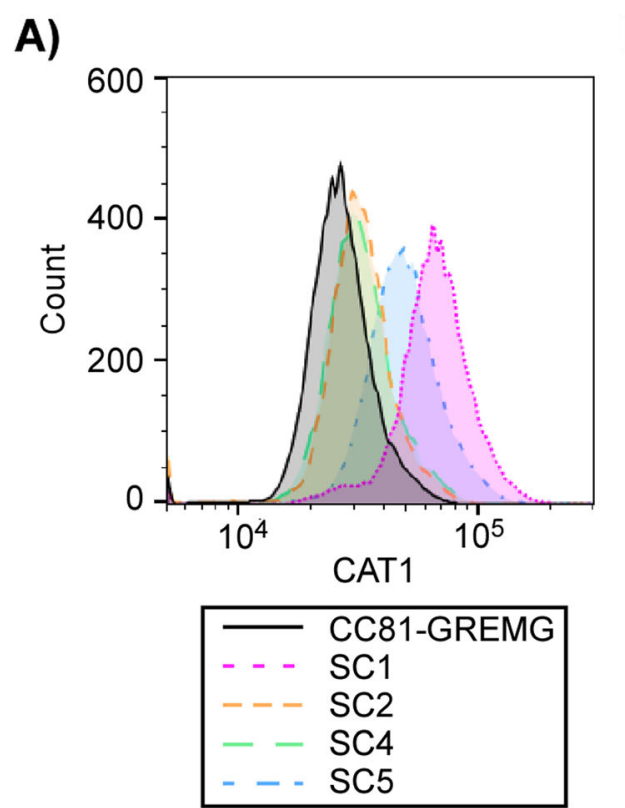

B)

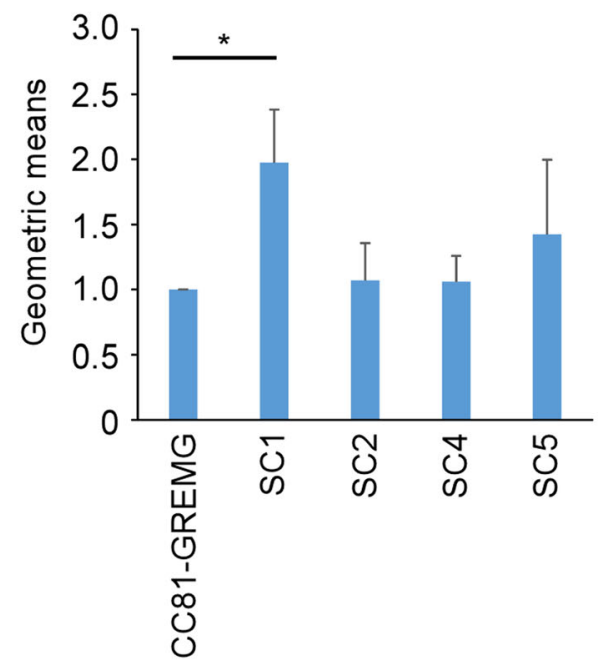

C)

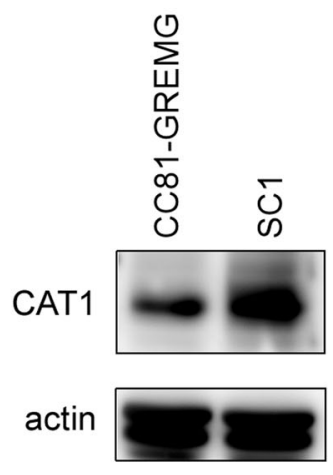

Fig. 1 CAT1 protein expression on CC81-GREMG cells and newly established bovine CAT1 stably transfected reporter cell clones. a CAT1 expression histogram of flow cytometric analysis. Four CAT1 stably transfected clones (SC1, SC2, SC4 and SC5) were fixed with 1\% formaldehyde/PBS and permeabilized with 0.1\% TritonX-100/PBS prior to staining with rabbit anti-CAT1 polyclonal antibody (Abcam, Cambridge, UK) and AlexaFluor 647 goat anti-rabbit antibody. Permeabilization allowed antibody binding to an intracellular region of CAT1 protein. CAT1 protein expression was measured with a BD Accuri C6sampler plus (BD Biosciences, San Jose, CA, USA) and analyzed by FlowJo software Ver.10 (FlowJo, LLC, Ashland, OR, USA). b Geometric mean expression of CAT1 in A. Mean and standard deviation of three independent experiments. The asterisk (*) represents a $p$-value of 0.05 . c Western blot analysis of CC81-GREMG and CAT1 stably transfected single clone SC1 cell with anti-CAT1 (upper panel) and anti- - -actin antibodies (bottom panel). CC81-GREMG and SC1 cells were lysed with lysis buffer ( $50 \mathrm{mM}$ Tris-HCl, pH 8.0, 150 mM sodium chloride, 0.5\% sodium deoxycholate, $0.1 \%$ sodium dodecyl sulfate (SDS), 1.0\% Nonidet P-40) and mixed with $4 x$ SDS-sample buffer. Ten micrograms of total protein were applied to 10\% SDS-polyacrylamide gel and transferred to a polyvinylidene difluoride membrane. CAT1 protein was detected by rabbit anti-CAT1 polyclonal antibody, horseradish peroxidase-conjugated rat anti-rabbit lgG antibody (Amersham Biosciences, Piscataway, NJ, USA), and SuperSignal ${ }^{T M}$ West Pico Chemiluminescent Substrate (Thermo Fisher Scientific) 
resistance gene using an In-Fusion HD cloning kit (TaKaRa Bio). The constructed plasmid was designated as pME-CAT1hyg and stably transfected into CC81-GREMG cell using Lipofectamine 3000 regent (Thermo Fisher Scientific). Transfected cells were cultured in Dulbecco's modified Eagle's Medium (Thermo Fisher Scientific) supplemented with $10 \%$ fetal bovine serum (Sigma-Aldrich, St. Louis, MO, USA), $250 \mu \mathrm{g} / \mathrm{mL}$ hygromycin B (Sigma-Aldrich), and $500 \mu \mathrm{g} / \mathrm{mL}$ G-418 (Roche, Basel, Switzerland) for several weeks. Single clones were selected by limited dilution in a 96-well culture plate until growth. Finally, four CAT1 stably transfected clones were established. To compare the expression level of CAT1 protein in the four clones, CAT1 expression was evaluated by flow cytometry with rabbit anti-CAT1 polyclonal antibody, which binds to an intracellular region of CAT1 protein followed by treatment with AlexaFluor 647 goat antirabbit antibody (Thermo Fisher Scientific). All CAT1 stably transfected clones showed higher expression of CAT1 protein than the parental cell line CC81-GREMG (Fig. 1a and b). Particularly, clone SC1 showed the significantly highest expression of CAT1 protein among the four clones. To confirm this result, CAT1 expression in CC81GREMG and SC1 cells was measured by western blot analysis with an anti-CAT1 antibody (Fig. 1c). The SC1 clone highly expressed CAT1 protein compared to CC81-

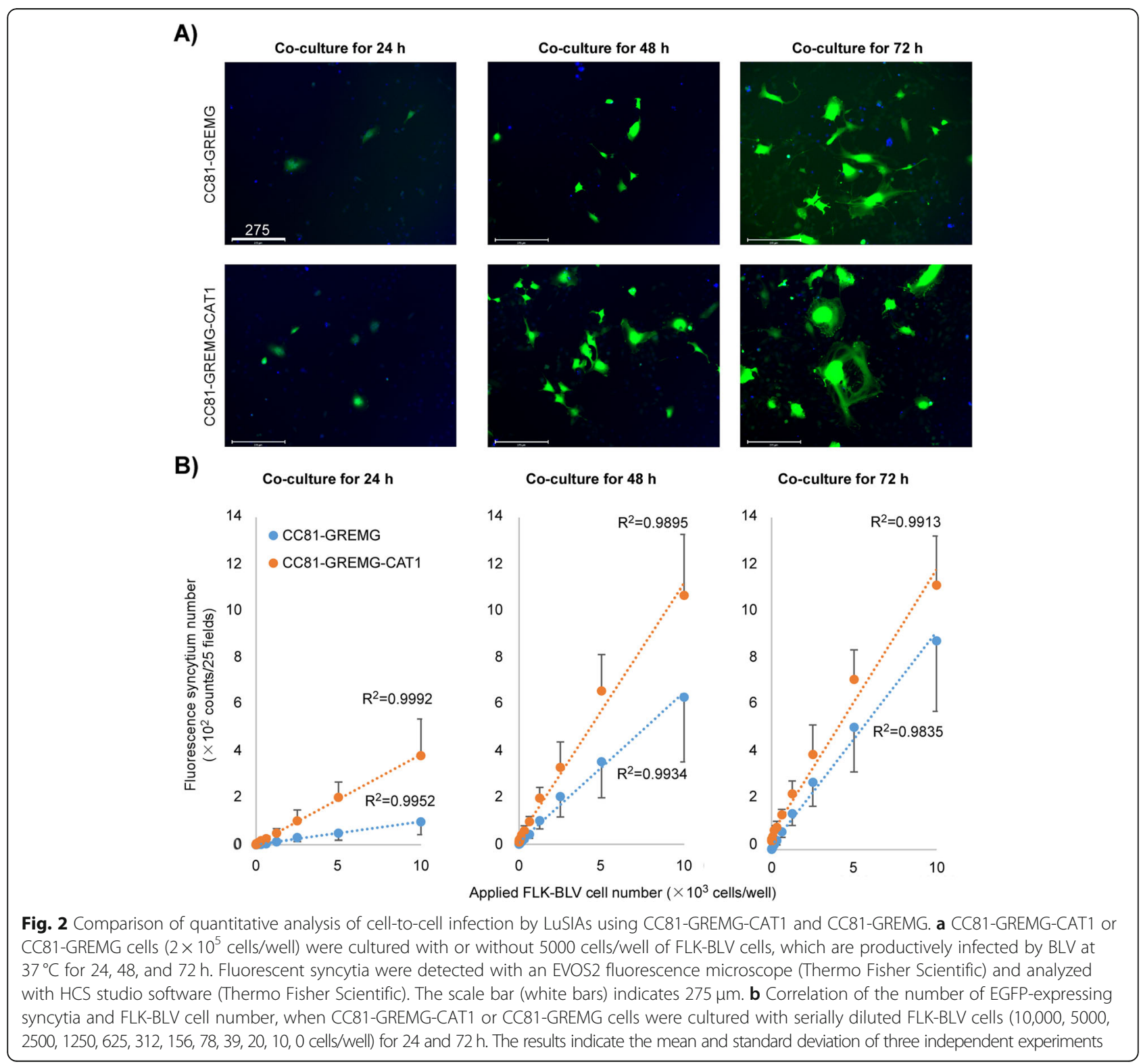




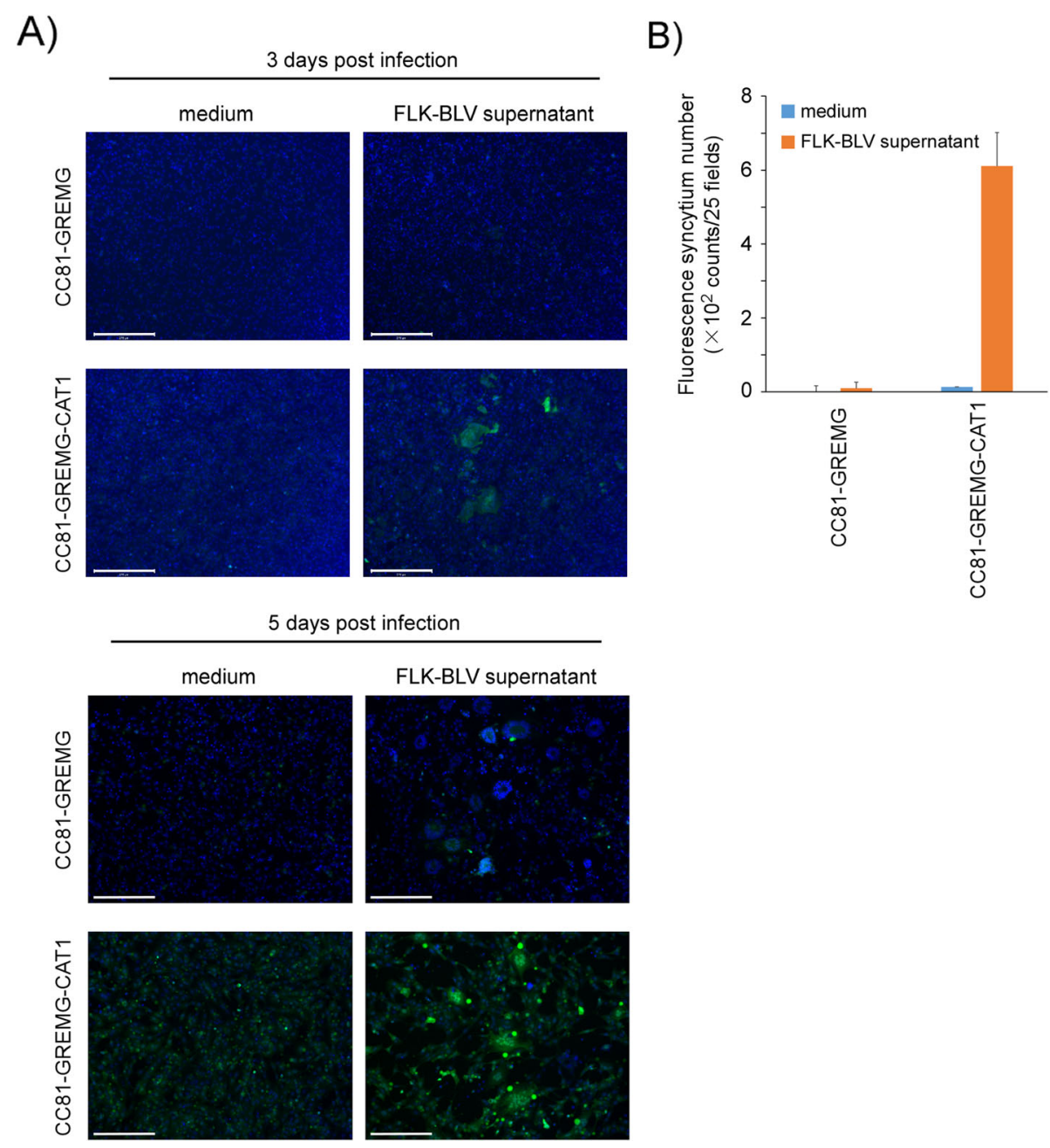

Fig. 3 Comparison of detection of cell-free infection by LuSIAs using CC81-GREMG-CAT1 and CC81-GREMG. a) CC81-GREMG-CAT1 and CC81GREMG cells $\left(4 \times 10^{5}\right.$ cells/well) were cultured with or without culture supernatant (containing $94 \mathrm{ng} /$ well of BLV p24 protein) collected from FLKBLV cells. The cells were cultured including $20 \mathrm{ng} / \mathrm{mL}$ of Hoechst 33342 (Sigma-Aldrich) and fluorescent syncytia are observed daily with an EVOS2 fluorescence microscope and analyzed with HCS studio software. The scale bar (white bars) indicate $275 \mu \mathrm{m}$. b Fluorescent syncytia were detected by LuSIAs using CC81-GREMG-CAT1 and CC81-GREMG at 3 days post-cultivation. The results indicate the mean and standard deviation of three independent experiments

Table 1 Development of luminescence syncytium induction assay

\begin{tabular}{|c|c|c|c|c|c|c|c|}
\hline methods & reporter cell lines & identification & $\begin{array}{l}\text { Non-specific } \\
\text { background }\end{array}$ & $\begin{array}{l}\text { BLV-infected } \\
\text { cells }\end{array}$ & $\begin{array}{l}\text { BLV } \\
\text { particle }\end{array}$ & $\begin{array}{l}\text { approved for milk } \\
\text { sample }\end{array}$ & references \\
\hline SIA & CC81, F81 & Giemsa staining & high & + & + & - & {$[21,22]$} \\
\hline LuSIA 1st. Gen. & CC81-BLU3G & $\begin{array}{l}\text { auto- } \\
\text { fluorescence }\end{array}$ & high & ++ & ++ & - & [23] \\
\hline $\begin{array}{l}\text { LuSIA 2nd. } \\
\text { Gen. }\end{array}$ & CC81-BLU3L & luciferase assay & low & ++ & ++ & NT & [24] \\
\hline $\begin{array}{l}\text { LuSIA 2nd. } \\
\text { Gen. }\end{array}$ & CC81-GREMG & $\begin{array}{l}\text { auto- } \\
\text { fluorescence }\end{array}$ & low & ++ & ++ & + & {$[24,25]$} \\
\hline $\begin{array}{l}\text { LuSIA 3rd. } \\
\text { Gen. }\end{array}$ & $\begin{array}{l}\text { CC81-GREMG- } \\
\text { CAT1 }\end{array}$ & $\begin{array}{l}\text { auto- } \\
\text { fluorescence }\end{array}$ & medium & +++ & +++ & NT & $\begin{array}{l}\text { this } \\
\text { report }\end{array}$ \\
\hline
\end{tabular}


GREMG cells. Therefore, we selected the SC1 clone as reporter cell line which was designated as CC81-GREMGCAT1.

Next, we evaluated the sensitivity of the 3rd generation LuSIA based on CC81-GREMG-CAT1. To compare the sensitivity of the newly developed reporter cell line CC81-GREMG-CAT1 and its parental reporter cell line CC81-GREMG, the cells were cultured with 5000 cells of FLK-BLV (a fetal lamb kidney cell line constitutively expressing BLV), which were infected by BLV for 24,48 , and $72 \mathrm{~h}$. Fluorescent syncytia were detected with an EVOS2 fluorescence microscope and analyzed with HCS studio software (Fig. 2a). At $24 \mathrm{~h}$ post-cultivation, in LuSIAs using both reporter cells, CC81-GREMG-CAT1 $(202.3 \pm 65.8$ counts/well) formed a larger number of fluorescing syncytia than CC81-GREMG $(48.7 \pm 29.9$ counts/well). Additionally, fluorescing syncytia by CC81GREMG-CAT1 were larger than those formed by CC81GREMG. The same tendencies were observed at 24,48 , and $72 \mathrm{~h}$ post- cultivation (Fig. 2a). Furthermore, to evaluate the sensitivity of CC81-GREMG-CAT1, both reporter cells were cultured with serially diluted FLKBLV cells for 24, 48 and $72 \mathrm{~h}$. In LuSIAs using both reporter cell lines, the number of fluorescent syncytia was strongly correlated with the number of FLK-BLV cells $\left(R^{2}=0.999\right.$ for CC81-GREMG-CAT1; $R^{2}=0.995$ for CC81-BLU3G) at $24 \mathrm{~h}$ post-cultivation (Fig. 2b). The numbers of fluorescent syncytia obtained by LuSIA were higher when using CC81-GREMG-CAT1 (381.7 \pm 157.1 to $2.3 \pm 1.5$ counts/well) than when using CC81-GREMG $(97.3 \pm 55.4$ to $0.7 \pm 0.6$ counts/well $)$ at $24 \mathrm{~h}$ postcultivation. The same tendencies were observed at 48 and $72 \mathrm{~h}$ post-cultivation (Fig. 2b). We previously reported that 2nd generation LuSIA using CC81-GREMG was more sensitive than the 1st generation LuSIA using CC81-BLU3G [24]. Our results demonstrated that CC81-GREMG-CAT1 is more suitable for analyzing cell-to-cell infectivity of BLV by LuSIA.

Previously, we reported that cell-free infection of the FLK-BLV supernatant was detectable by LuSIA using CC81-GREMG after 5 days of cultivation [24]. Here, we attempted to use CC81-GREMG-CAT1 cells to detect cell-free infection of BLV by decreasing the co-culture time to 3 days from 5 days using 2 nd generation LuSIA based on CC81-GREMG. CC81-GREMG-CAT1 and CC81-GREMG were cultured with $20 \mathrm{ng} / \mathrm{mL}$ of Hoechst 33342 and infected with culture supernatant collected from FLK-BLV cells. The fluorescent syncytia were clearly detected in CC81-GREMG-CAT1 at 3 days postcultivation, whereas fluorescent syncytia were detected in CC81-GREMG at 5 days post-cultivation (Fig. 3a and b), indicating that CC81-GREMG-CAT1 shows more rapid results with higher sensitivity for BLV cell-free infection than CC81-GREMG. This result indicates that the 3rd generation LuSIA based on CC81-GREMGCAT1 can detect infectious BLV particles within 3 days, which was not detected by 2nd generation LuSIA.

Our result confirmed the hypothesis that overexpression of the BLV receptor bovine CAT1 enhances the cellular susceptibility to BLV infection, thereby increasing the sensitivity of LuSIA. (i) CC81-GREMG-CAT1 can detect cell-free infection of BLV at an earlier time point by decreasing the co-culture time to 3 days from 5 days using in 2nd generation LuSIA based on CC81-GREMG. (ii) CC81-GREMG-CAT1 is more suitable for analyzing the cell-to-cell infectivity of BLV by LuSIA, as CC81GREMG-CAT1 formed a larger number and bigger fluorescing syncytium than CC81-GREMG. Thus, the new LuSIA protocol using the 3rd generation reporter cell line CC81-GREMG-CAT1, which showed higher expression of the BLV receptor CAT1, is advantageous for earlier and sensitive detection of both cell-to-cell and cell-free infection of BLV (Table 1.). Additionally, this assay can be further developed to visualize the infectivity of BLV in a more sensitive and/or rapid manner, such as in a BLV contamination contradiction assay of bovine vaccines.

\section{Abbreviations}

BLV: Bovine leukemia virus; CAT1: cationic amino acid transporter 1 ; EGFP: enhanced green fluorescent protein; FLK: fetal lamb kidney; GREMG: glucocorticoid response element mutated reporter cording with EGFP; LTR: long terminal repeat; LuSIA: luminescence syncytium induction assay; PBS: phosphate-buffered saline; SDS: sodium dodecyl sulfate; SIA: syncytium induction assay

\section{Acknowledgments}

The authors thank all members of the virus infectious disease unit of RIKEN. We are grateful to the Support Unit, Bio-material Analysis, RIKEN BSI Research Resources Center, for helping with sequence analysis. We would like to thank Editage (www.editage.com) for English language editing.

\section{Authors' contributions}

HS and YA conceived and designed the experiments. HS, LB and LB performed the experiments and analyzed the data. $\mathrm{HS}$ and YA wrote the manuscript. All authors read and approved the final manuscript.

\section{Funding}

This study was supported by Grants-in-Aid for Scientific Research (A), (C) and Young Scientists (B) from the Japan Society for the Promotion of Science (JSPS) [Grant Nos. JP16H02590, JP19K06450 and JP17K18356], and by grants from the Project of the NARO Bio-oriented Technology Research Advancement Institution (special scheme regarding regional development strategies) [Grant No. 16817983], and (the special scheme project on vitalizing management entities of agriculture, forestry and fisheries) [Grant No. 16930548].

\section{Availability of data and materials}

All data analyzed for the purposes of this manuscript are included in this article.

Ethics approval and consent to participate

Not applicable.

Consent for publication

Not applicable.

Competing interests

The authors declare that they have no competing interests. 


\section{Author details}

Nakamura Laboratory, Baton Zone Program, RIKEN Cluster for Science, Technology and Innovation Hub, 2-1 Hirosawa, Wako, Saitama 351-0198, Japan. ${ }^{2}$ Virus Infectious Diseases Unit, RIKEN, 2-1 Hirosawa, Wako, Saitama 351-0198, Japan. ${ }^{3}$ Photonics Control Technology Team, RIKEN Center for Advanced Photonics, 2-1 Hirosawa, Wako, Saitama 351-0198, Japan.

Received: 23 October 2019 Accepted: 8 April 2020

Published online: 22 April 2020

\section{References}

1. Aida Y, Murakami H, Takahashi M, Takeshima S-N. Mechanisms of pathogenesis induced by bovine leukemia virus as a model for human Tcell leukemia virus. Front Microbiol. 2013;4:328.

2. Erskine RJ, Bartlett PC, Byrem TM, Render CL, Febvay C, Houseman JT. Using a herd profile to determine age-specific prevalence of bovine leukemia virus in Michigan dairy herds. Vet Med Int. 2012;2012:350374.

3. Polat M, Moe HH, Shimogiri T, Moe KK. Takeshima S-n, Aida Y. the molecular epidemiological study of bovine leukemia virus infection in Myanmar cattle. Arch Virol. 2017;162:425-37.

4. Polat M, Ohno A, Takeshima SN, Kim J, Kikuya M, Matsumoto Y, et al. Detection and molecular characterization of bovine leukemia virus in Philippine cattle. Arch Virol. 2015;160(1):285-96.

5. Polat M, Takeshima S-N, Aida Y. Epidemiology and genetic diversity of bovine leukemia virus. Virol J. 2017;14:209.

6. Polat M, Takeshima S-N, Hosomichi K, Kim J, Miyasaka T, Yamada K, et al. A new genotype of bovine leukemia virus in South America identified by NGS-based whole genome sequencing and molecular evolutionary genetic analysis. Retrovirology. 2016;13:1-23.

7. Yang Y, Fan W, Mao Y, Yang Z, Lu G, Zhang R, et al. Bovine leukemia virus infection in cattle of China: association with reduced milk production and increased somatic cell score. J Dairy Sci. 2016;99(5):3688-97.

8. Erskine RJ, Bartlett PC, Byrem TM, Render CL, Febvay C, Houseman JT. Association between bovine leukemia virus, production, and population age in Michigan dairy herds. J Dairy Sci. 2012;95:727-34.

9. Domenech A, Goyache J, Llames L, Paya MJ, Suarez G, Gomez-Lucia E. In vitro infection of cells of the monocytic/macrophage lineage with bovine leukaemia virus. J Gen Virol. 2000;81:109-18.

10. Mirsky ML, Olmstead CA, Da Y, Lewin HA. The prevalence of proviral bovine leukemia virus in peripheral blood mononuclear cells at two subclinical stages of infection. J Virol. 1996;70:2178-83.

11. Panei CJ, Takeshima S-N, Omori T, Nunoya T, Davis WC, Ishizaki H, et al. Estimation of bovine leukemia virus (BLV) proviral load harbored by lymphocyte subpopulations in BLV-infected cattle at the subclinical stage of enzootic bovine leucosis using BLV-CoCoMo-qPCR. BMC Vet Res. 2013;9:95.

12. Schwartz I, Bensaid A, Polack B, Perrin B, Berthelemy M, Levy D. In vivo leukocyte tropism of bovine leukemia virus in sheep and cattle. J Virol. 1994;68:4589-96.

13. Stott ML, Thurmond MC, Dunn SJ, Osburn BI, Stott JL. Integrated bovine leukosis proviral DNA in Thelper and T cytotoxic/suppressor lymphocytes. J Gen Virol. 1991;72:307-15.

14. Willems L, Grimonpont C, Kerkhofs P, Capiau C, Gheysen D, Conrath K, et al. Phosphorylation of bovine leukemia virus tax protein is required for in vitro transformation but not for transactivation. Oncogene. 1998;16(17):2165-76.

15. Williams DL, Amborski GF, Davis WC. Enumeration of T and B lymphocytes in bovine leukemia virus-infected cattle, using monoclonal antibodies. Am J Vet Res. 1988:49:1098-103.

16. Wu D, Takahashi K, Murakami K, Tani K, Koguchi A, Asahina M, et al. B-1a, B$1 \mathrm{~b}$ and conventional $\mathrm{B}$ cell lymphoma from enzootic bovine leukosis. Vet Immunol Immunopathol. 1996;55:63-72.

17. Aida Y, Okada K, Amanuma H. Phenotype and ontogeny of cells carrying a tumor-associated antigen that is expressed on bovine leukemia virusinduced Lymphosarcoma. Cancer Res. 1993;53(2):429-37.

18. Inabe K, IKuta K, Aida Y. Transmission and propagation in cell culture of virus produced by cells transfected with an infectious molecular clone of bovine leukemia virus. Virology. 1998;245:53-64.

19. Bai L, Sato H, Kubo Y, Satoshi W, Aida Y. CAT1/SLC7A1 acts as a cellular receptor for bovine leukemia virus infection. FASEB journal : official publication of the Federation of American Societies for Experimental Biology. 2019;133:12.
20. Closs El, Boissel JP, Habermeier A, Rotmann A. Structure and function of cationic amino acid transporters (CATs). J Membr Biol. 2006;213(2):67-77.

21. Ferrer JF, Cabradilla C, Gupta P. Use of a feline cell line in the syncytia infectivity assay for the detection of bovine leukemia virus infection in cattle. Am J Vet Res. 1981;42:9-14.

22. Graves DC, Jones LV. Early syncytium formation by bovine leukemia virus. J Virol. 1981;38(3):1055-63.

23. Sato H, Watanuki S, Murakami H, Sato R, Ishizaki H, Aida Y. Development of a luminescence syncytium induction assay (LuSIA) for easily detecting and quantitatively measuring bovine leukemia virus infection. Arch Virol. 2018; 163(6):1519-30

24. Sato H, Watanuki S, Bai L, Borjigin L, Ishizaki H, Matsumoto Y, et al. A sensitive luminescence syncytium induction assay (LuSIA) based on a reporter plasmid containing a mutation in the glucocorticoid response element in the long terminal repeat U3 region of bovine leukemia virus. Virol J. 2019;16(1):66.

25. Watanuki S, Takeshima SN, Borjigin L, Sato H, Bai L, Murakami H, et al. Visualizing bovine leukemia virus (BLV)-infected cells and measuring BLV proviral loads in the milk of BLV seropositive dams. Vet Res. 2019;50(1):102.

\section{Publisher's Note}

Springer Nature remains neutral with regard to jurisdictional claims in published maps and institutional affiliations.

Ready to submit your research? Choose BMC and benefit from:

- fast, convenient online submission

- thorough peer review by experienced researchers in your field

- rapid publication on acceptance

- support for research data, including large and complex data types

- gold Open Access which fosters wider collaboration and increased citations

- maximum visibility for your research: over $100 \mathrm{M}$ website views per year

At BMC, research is always in progress.

Learn more biomedcentral.com/submissions 